\title{
THE IMPORTANCE OF THE MUTUAL ROLE BETWEEN THE INSTITUTIONS OF CIVIL SOCIETY AND THE APPLIED ARTS IN TEACHING THE DESIGN OF ARCHITECTURAL
} Rand Rushdi YOAKIM *

Higher Institute of Applied Arts, Fifth Settlement, Egypt

\begin{abstract}
One of the most important areas that are taught in colleges and institutes of applied arts is design materials, with all its branches, and the design of architectural spaces is one of those materials that are concerned with case studies and the work of a plan of needs and functions. A human space in which one or more human activities are practiced, with the development of humanity and the development Activities and their fields, develop with them the types of spaces that serve those activities, and provide the recipient with an appropriate design environment (and a functional course) suitable, and perhaps in the field of designing architectural spaces.
\end{abstract}

Keywords

The Mutual Role, The Institutions Of Civil Society, The Applied Arts, The Design Of Architectural.

\section{Introduction:}

the job is one of the aspects of design and its connection to the design process is a strong and important link to achieve the purpose of the architectural void, and follow the technological development in Architectural fields and methods of building and finishing tremendous development required the designer to be fully aware of these developments, materials and methods of implementation and preparation for that, from preliminary drawings through successive design processes to executive drawings, and the process of teaching design materials was far from the actual application side or the real employment of design materials Apart from the default layouts for a site or project it is difficult to make The one in charge of teaching moves away from it and prefers the hypothetical plans for a place or site, and these projects end up like the previous ones in the listing or the wall, or even in files hidden among the computer files in preparation for disposal after a period of time.

And because these design materials have a close relationship with civil society organizations that would sponsor these designs and projects until they came to light through the actual implementation of them, so it was necessary for us to pave the way for that cooperation and exchange of experiences between teaching design materials for architectural spaces and civil society institutions as a sponsor and incubator for those ideas and a way. To implement them on the ground, which makes these projects valuable in community service, and the design process takes the appropriate professional dimension.

* Corresponding author: appliedarts@aai.edu.eg 


\section{Research Problem:}

1- Drain the creative energies of design materials in unreal (hypothetical) projects without realworld implementation.

2- The lack of a deliberate plan for cooperation between the bodies that teach design materials for architectural spaces and institutions that sponsor, support and bring these ideas to light.

3- The efficiency of the teaching process in some agencies and the efficiency of the productive projects is not up to the level that qualifies it for actual implementation due to the lack of interest in the changing market requirements.

Community participation and civil society institutions:

During the last two decades, the issue of civil society and its institutions has received great attention by researchers in the field of social sciences, and attention has sometimes focused on the concept, its rooting and research in the perspective that explains it and defines the fields of work in it, and sometimes on community organizations as a mechanism of social action at the level of the lived reality.

The fact that is not lost on those interested is that the increased interest in civil society and organizations linked in one way or another to the increased interest of the international community in this matter, as the civil society sector became not only emerging as an effective force at the national level, but was characterized by diversity in its nature, composition and impact on social and political life in many parts of the country. Countries of the world especially with the great development in the information and communication revolution. Reports issued by the United Nations and the World Bank show that the number of civil society organizations was in 1990 (6000) organizations, which rose to 50 thousand in 2006.

Nevertheless, the term "civil society: not precisely defined, as it is often talked about and used with different meanings raises great confusion and a strong contradiction between reverence and contempt, or support and condemnation." As for the term itself, the term civil society appeared in The Ancient Dictionary of Humanity according to the Romans (11), and then disappeared after that to reappear in the seventeenth and eighteenth centuries, and John Locke may have been the first to use it after the English Revolution of 1688, in his famous text (The Letter of Tolerance, 1689), and then successively. A number of philosophers, sociologists, and Western politicians such as Hobbes, Rousseau and Hegel, and others, was born in the light of the radical transformation that swept Europe and the transition from the dark age to the era of the modern state and the new order. Then he reappeared to coincide with the beginnings of the transformation in Europe Eastern Union, so it was launched from Poland (1982), when the Solidarity Union presented itself as one of the organizations of civil society. 
Salim (4:37) defined civil society as "encompassing a wide range of social and professional organizations. These community organizations contain a variety of formal and informal entities, starting from political parties, professional and labor unions, civil associations and charitable sectors, such as the endowment and the Hisbah institutions and ending with international and professional gatherings." And chambers of commerce and industry, cooperative and agricultural societies, clubs, youth centers, and cultural houses, "and accordingly, we find that the types of project management and contracting companies represent the official and well-known entities that carry out service and commercial projects of the types of civil and community organizations spread in the Egyptian society that operate and manage projects.

As for the impact of those community-based institutions on educational institutions, Peterson's study (2005) (9 - 55) referred to the method of influencing students outside educational institutions and the relationship between society and the university to develop morals and citizenship. The study was applied to young people in the southern United States of America to learn ways of thinking Young people, their rights and duties towards their society, their ideas, tendencies, behavior and aspirations for the future. The study found that paying attention to the needs of young people and developing their scientific knowledge, achieving cooperation between the university and community institutions, and helping young people in sound thinking helped in developing the values of citizenship and belonging to them, and it is one of the goals that the protocol sought to deepen the students' sense of belonging to their community represented in one of the projects The engineering in which the student finds himself participating in his design and watching his designs are implemented on the ground and following up on the design and implementation variables first hand.

Community participation as one of the requirements for obtaining quality education:

The pursuit of educational institutions to obtain quality education through the Quality Assurance Authority. Higher education institutions are associated with a number of criteria, perhaps the most important of which are on the scope of the institution's activity outside its borders, its extension to the community and measuring its impact on the surrounding community is the criterion of community participation, which seeks to measure the impact of the institution outside its walls, and its impact. Influencing the performance of the institution, measuring the level of students and the skills they acquired and comparing that with the labor market, as well as measuring the suitability of students with all their knowledge of the labor market in all its development and developments. This supports the idea of community participation and its importance for both the educational institution and the community 
institution, hence the importance of this research by activating that role and theorizing it in a way that allows everyone to benefit from its steps and follow them to achieve the desired goals of participation.

Partnership and mutual role between educational institutions and community institutions:

"Community participation in education means the contribution of society with all its institutions, individuals and groups to the development of the educational process, and to clarify the importance of community participation in the field of education. We find that education in the past was largely dependent on donations from individuals and civil society institutions (10), and today, with the increasing needs and development in The fields of education and scientific research have become necessary to activate these participations. Education is no longer far from society with its various institutions. Rather, today we see that the main product of higher education institutions is the student, and arm him with everything new in the fields of design, implementation and technology (with regard to graduates of technical colleges). The interest of society as a whole, so everyone must participate in the production of a designer capable of presenting the new in terms of deposit and thinking armed with what he has gained from modern design sciences through participation with institutions and supporting bodies.

Partnership can also be defined as the state in which a partner participates in the same activity, and this partner may be an individual, group or institution. It is also defined as common interests or contractual relationships based on mutual agreements in response to developmentrelated priorities while achieving transparency and accountability principles, in light of coordination with all participants in development processes.

Salim $(4-36,37)$ defined the concept of partnership as more than a contract between two or more to carry out joint work, it means concerted efforts of the government with the private, civil and charitable sectors at the national or regional level in facing any problem through effective communication. (Effective communication) to reach an agreement with cooperation (Cooperation) to reach an acceptable formulation for this partnership, whether this matter is bound by a contract (formal participation), or cooperation bound by informal partnership values, and participation in resources and strengthening the roles of all participating parties comes through coordination ( Coordination) up to effective participation in the actual implementation in the preparation, implementation and follow-up of the plan, policies, goals, programs, projects and activities.

Barbara A. (2001) identified. Holland has the characteristics of effective and continuous partnerships, as follows: "It is based on discovering and defining common goals and interests 
between the parties, through which a common agreement is reached, and an equivalent action plan is developed cooperatively between the parties. The expectations and capabilities of each party are made. The results are clear and successful in measuring Each of the institutional and societal aspects that represent the outcomes of the partnership, the participation in the control and management of the partnership trends and the available resources, the focus on the strengths that each party has, the identification of opportunities available to achieve early success, the focus on the two-dimensional vision, which is concerned with the exchange of experiences, learning and capacity building, and attention The process of communication, trying to instill confidence between the parties, and commitment to the continuous evaluation of the partnership process, as well as the outputs (7-10). Joseph Yad (2002) (6-3,4) believes that "one of the most important steps to achieve a successful partnership is to define and agree on objectives. From the long experience of universities that have adopted participation and cooperation with community institutions, their members have formed a conviction that there is a need for a common understanding of the fundamentals of the issues because the difference is about the objectives or the conflict and the conflict in Thoughts is the fastest way to fail posts: There is no doubt that the recent development of community institutions and companies with small and large entities and its direct impact on economic development can be exploited; That is why the partnership relationship between university education in all its institutions, including governmental and private institutes, universities and colleges, and between community institutions, including public and private institutions, and small, medium or large economic entities, is extremely important. As this relationship is considered one of the main components of the development of societal sectors on the one hand, and the development of teaching and learning skills and methods, especially with regard to applied studies, which depend on students' acquisition of basic skills in design in addition to implementation skills, manufacturing and installation technology, and experiences of selecting materials and employing them properly and modernly in a way that suits development. In the global production and implementation technology, which is constantly renewed and introduces methods and raw materials, which requires partnership and exchange of experiences between the two sides of the project, namely the design and preparation of preparatory and final drawings represented in the academic aspect or higher education institutions related to the arts, the point of implementation, development and translation of drawings and designs into projects implemented on The reality is represented by civil society companies and institutions. "This partnership has enabled tremendous innovations that have been the basis for the tremendous development taking place in advanced economies. In these economies, the decision-maker 
turns to university education institutions to conduct studies and systematic comparison of problems faced by community institutions, and this methodology in the relationship has led to the establishment of traditions and values. For decision-making, which resulted in a quantitative and qualitative accumulation of information that made university education institutions and their research an integral part of comprehensive development (1-710). This partnership or reciprocal roles has characteristics that distinguish it, identified by Farid AlNajjar (1999) in that it is: "of an reciprocal and cooperative character; Where each member offers his best for the success of the partnership to the other party, and relations between partnerships must be organized on horizontal and vertical basis for the purpose of exchanging technology and building a strong base of necessary resources.

The mutual roles between community institutions and higher education institutions in designing architectural spaces:

The principle of participation in the design of architectural spaces depends on contributing to the achievement of development goals of community institutions in light of the state's interest in this field $(2-630,631)$ and the complementarity of the role of the members of the research team (design), the supporting bodies and the beneficiaries, which results in collecting all the expertise and capabilities available for the project. Research (design) in one crucible, resulting in high-quality outputs that cannot be achieved by each team.

It also requires providing an opportunity for researchers (designers who are students of the fourth year - Department of Decoration) to gain more experience and skills from the participating researchers who are the most knowledgeable and knowledgeable, and this acquired experience may be an asset for them in implementing future research projects, and it is important to mention that some of these experiences It is acquired through the actual practice of the research process, and it cannot be gained through viewing published research (previous work from the implemented projects). The partnership also allows researchers to benefit from specialized technical expertise in which the private sector has achieved a high leap $(5-23,24)$. This is what we sought to achieve through the bachelor's batch of decoration project in 2018 at the Higher Institute of Applied Arts. The search was for a way to partner and exchange roles between the educational institution entrusted with teaching students and providing them with the skills needed for the job market, represented in the graduation project, and the basic vision of partnership and interest in the role was Mutual education between different educational institutions and civil society institutions represented by major project companies achieving the basic purposes of the partnership, namely:

1- Empowering students of the fourth year in the decoration department of the institute in their 
final design production and learning to deal with realistic problems represented in a project on the ground with its challenges and modern building systems, and to contribute to finding appropriate solutions to them.

2- Assisting the community activity with scientific methods that lead to the development and creation of new methods resulting in the abundance of society and its improvement, especially with the existence of one of the design problems of the commercial center subject of the protocol, which is how to reach a suitable design for the main entrance space that carries what the place requires of design space and attraction Suitable for visitors to the place.

3- Linking the strategy of scientific research and community participation in universities with the problems and requirements of the comprehensive development of community institutions. 4- Reaching out to a system that ensures continuous communication and coordination between the Higher Institute of Applied Arts - Fifth Settlement (represented by the Decoration Department) and the community institutions.

5- Ensuring the utilization of the resources and capabilities available in the community institutions in developing the research system.

The institute has the honor to conclude a cooperation protocol between the esteemed Arabella Company for Tourism and Urban Development and the Higher Institute of Applied Arts - Fifth Settlement, provided that the protocol agreement stipulates the following items:

First Clause:

The first party undertakes to make interior designs, treatments for the walls, interior and exterior façades, and vacuum treatments for the landscape areas of the mall for the students of the institute for the project subject, and to follow up on the developments of the project on the site under the supervision of the material professor MD / Raed Rushdi Yoakim. M / Sara Ibrahim from the assisting body and Eng / Mourad Helmy from Arabella Company for Tourism and Urban Development or whoever is on his behalf from the site's engineers.

- The second item:

That the second party is obligated to provide the general plan of the commercial center and all the architectural and construction details that clarify the internal and external spaces, corridors and architectural blocks.

Third Clause:

For the second party to participate with the professor of the subject MD / Raed Rushdie, to determine the proposed places for the implementation of the project on the site.

- $\quad$ Fourth item:

For the first party to present the project designs to the second party for approval and to add any 
suggested amendments, and the second party participates with the first party in evaluating students 'projects.

Fifth:

This protocol is valid throughout the current academic year 2017-2018 AD, provided that it starts from the date of signing it, and is renewed based on the desire of the parties to achieve more cooperation and participation, and it can be renewed for another academic year with the consent of both parties.

Sixth Clause:

This protocol is to be written in two original copies (none of them shall be recognized), and each party shall receive a copy to act accordingly.

- A second party

- First party Prof. Dr. Khaled Ali Owais, Dean of the Higher Institute of Applied Arts, Fifth District, Mr. Eng. Murad Helmy, Director of the Technical Office of Arabella Company for Tourism and Urban Development. Accordingly, the actual implementation of the design steps and the follow-up of developments has begun with the authority responsible by the company to follow up represented in M / Murad Helmy - Executive Director of the project, and his assistants from the design and implementation engineers at the site, and the following is the model of the stages of design and presentation of the project through a model of the project that was chosen by the company to implement the site, and to provide the opportunity for the student project owner to work for the company and follow up the implementation of the project on the ground Indeed .

\section{References:}

1- Hamza Mahmoud Al-Zubaidi: "Integration of the System of Interaction between Societal Sectors and Institutions of Higher Education and Applied Research", published research, Second Conference for Planning and Development of Education and Scientific Research in the Arab Countries, Volume 2.

2- Rabi` Abdul-Ra'f Amer: “A proposal to develop the relationship between scientific research in universities and community institutions", the second conference on planning and developing education and scientific research in the Arab countries, Volume 2, King Fahd University of Petroleum and Mining, Dhahran, Saudi Arabia, February 24-27, 2008 .

3- Farid Al-Najjar: "Strategic Alliances from Competition to Cooperation... Choices of the Twenty-First Century”, Al-Mashreq Publishing House, 2006.

4- Muhammad Al-Asma`i Mahrous Salim, "Educational Reform and Contemporary Community Partnership from Concepts to Application", Dar Al-Fajr for Publishing and 
Distribution, Cairo, 2005.

5- Muhammad bin Ibrahim Al-Siyal: "Challenges for establishing effective community partnership in the field of scientific research in the field of the Kingdom of Saudi Arabia", the experience of King Abdulaziz City for Science and Technology.

6- Youssef Syed Mahmoud Eid: "Dimensions and Problems of Partnership between the University and Some Community and Service Institutions", Fourth Scientific Conference: Education and the Future of Human Development in the Arab World, College of Education, Fayoum University, October 21-22.

7- arbara A. Holland; Characteristics of "Engaged Institutions" and Sustainable Partnerships, and Effective Strategies for Change, Office of University Partnerships, Indiana University, Indiana, March 2001, P. 10

8- Bruce L. Mallory, Reflections on the Wingspread Experience, U.S. Department of Housing and Urban Development, Office of Policy Development and Research, Washington DC, March 2002, P. 26.

9- Peterson Donna (2005), Pathways of influence in out of school time Community University partnership to develop Ethics new directions for youth development.

10- https://www.new-edu.com

11- https://www.greatbuildings.com

12- https://www.archdaily.com

13- Sabreen Samir SAAD, THE EFFECTIVENESS OF A PROPOSED PROGRAM BASED ON BLENDED LEARNING TO DEVELOP ACHIEVEMENT IN WESTERN MUSIC GRAMMAR FOR STUDENTS OF THE FACULTY OF SPECIFIC EDUCATION, International Journal of Education and Learning Research, Vol. 2, No. 2, 2019, pp. 41-47. 